\title{
Estimation and Comparison of the Duration of the Pubertal Peak in Skeletal Class II and Class I Subjects Using the Cervical Vertebrae Maturation Index Method
}

\author{
Hasna Ghaleb ${ }^{1}$, Roula $A k I^{2}$, Elie Khoury ${ }^{3}$, Joseph Ghoubril ${ }^{4}$
}

\begin{abstract}
Aim: The purpose of this study is to estimate and compare the duration of the pubertal peak in skeletal class II and class I subjects and to detect any difference between boys and girls or between hypo-, normo-, and hyperdivergent subjects for skeletal maturation indicator (CVM) in white Caucasians.

Materials and methods: 346 subjects were selected from 3,119 examined files. Pretreatment lateral cephalometric records were hand-traced and divided following the anteroposterior skeletal relationship, the gender, the vertical pattern, and the skeletal maturation. The duration of the pubertal peak was calculated based on the chronological age interval according to each group. The age of onset of the active growth and the duration of the pubertal peak were compared between the different groups studied.

Results: Pubertal peak had a mean duration of 13 months in skeletal class I subjects, 19 months in skeletal class II subjects, 15 months in girls, 20 months in boys, 13 months in normodivergent and hypodivergent subjects, whereas in hyperdivergent subjects, it lasted 18 months.

Conclusion: The growth interval corresponding to the pubertal growth spurt (CS3-CS4) was (1) significant between skeletal class I and class II subjects, (2) longer in boys, and (3) longer in hyperdivergent subjects.

Clinical significance: Orthodontic treatments can start earlier for girls in class I or class II relationship and for hyperdivergent subjects as well. Furthermore, boys and subjects in class II skeletal relationship have a significantly longer duration of the pubertal peak and consequently a much efficient orthopedic and orthodontic treatment.
\end{abstract}

Keywords: Cervical vertebrae maturation, Class I and class II subjects, Pubertal peak, Retrospective cross-sectional study, Skeletal age.

The Journal of Contemporary Dental Practice (2019): 10.5005/jp-journals-10024-2637

\section{INTRODUCTION}

Growth potential and duration of the pubertal peak are the primary factors in establishing an orthodontic treatment plan. This period exists in all individuals but has variable characteristics (onset, duration, and magnitude). ${ }^{1,2}$ Several authors have tried to estimate it through biological growth indicators, ${ }^{2-4}$ which have been the subject of various studies to provide orthodontists with a valid, efficient, and reproducible reference. Two types of indicators were used: the chronological age and the biological age. The first indicator is a subject of controversy. ${ }^{2-7}$ The second one involves various factors: the statural age ${ }^{1,3,8-10}$ the sexual age ${ }^{11,12}$ the dental age, ${ }^{13-17}$ and the bone age and is the most reliable indicator for use in orthodontics.

For many years, orthodontists used the hand and wrist maturation index to determine bone age.

However, even with the reliability of this indicator, there are still some uncertain clinical predictabilities, ${ }^{18}$ the most important being the impossibility of growth prediction ${ }^{10}$ as well as the harmful additional radiation exposure especially to growing subjects. ${ }^{19}$

Therefore, Lamparski launched a "new indicator," 20 the cervical vertebrae maturation index (CVM). Later on, this idea was developed and improved by several authors ${ }^{21-24}$ until it reached its actual version with the method presented by Baccetti et al. This method has proven to be reproducible because it is easy to learn and to apply. ${ }^{25,26}$

These authors showed that the mandible expresses maximal growth during the pubertal peak interval, between CVM3 and
${ }^{1}$ Private Practitioner of Orthodontics in Beirut, Lebanon

${ }^{2-4}$ Department of Orthodontics, Faculty of Dental Medicine, SaintJoseph University of Beirut, Beirut, Lebanon

Corresponding Author: Elie Khoury, Department of Orthodontics, Faculty of Dental Medicine, Saint-Joseph University of Beirut, Beirut, Lebanon, Phone: +009613525768, e-mail: elie.khoury@usj.edu.lb

How to cite this article: Ghaleb $\mathrm{H}, \mathrm{Akl} \mathrm{R}$, et al. Estimation and Comparison of the Duration of the Pubertal Peak in Skeletal Class II and Class I Subjects Using the Cervical Vertebrae Maturation Index Method. J Contemp Dent Pract 2019;20(9):1095-1101.

Source of support: Nil

Conflict of interest: None

CVM4, justifying the necessity and effectiveness of treating growing patients at the pubertal peak or slightly after.

The determination of the pubertal peak period is in fact necessary, but the duration of this period is more essential to quantify the number of months during which growth is accelerated and therefore to know the magnitude of the orthopedic response following the orthodontic therapy. ${ }^{27}$

Literature provides us with information about the duration of the growth in skeletal class III Caucasian subjects compared to skeletal class $1^{28}$ while information concerning the duration of the pubertal peak in skeletal class II subjects is still lacking.

The purpose of this study is to estimate and compare the duration of the pubertal peak in skeletal class II and class I subjects 
and to detect any differences between boys and girls or between hypo-, normo-, and hyperdivergent subjects for skeletal maturation indicator (CVM) in white Caucasians.

\section{Materials and Methods}

\section{Sample}

This is a retrospective cross-sectional study.

The sample size was calculated considering the comparison of two means for the sample size estimation with a two-sided significance level of 0.05 , a standard deviation of 8 months, a precision of 5 months, and a power of $95 \%$. The expected variance was obtained from a pilot study based on the duration of the adolescent peak growth spurt in class II between stages CVM3 and CVM4. The required minimal number was 67 persons per group.

3,119 records of orthodontically untreated subjects from the archive of the Orthodontic Department were examined, from the most recent ones to the oldest (till year 2000), for the possible inclusion.

346 cases (131 boys and 215 girls) presenting the inclusion criteria were selected and divided into 4 groups according to their skeletal classes of malocclusion and to their cervical vertebral maturation (class I-CVM3 =96; class I-CVM4 $=102$; class II-CVM3 =75; class II-CVM4 = 73).

All the patients filled an informed consent form in order to have the permission to use their X-rays in our study. Sample was then divided into gender groups as a first step and later into vertical growth pattern groups as a second step, in order to determine any significant difference between the groups for the duration of the pubertal growth.

In order to be included in the study, the patient must age between 8 and 18 years, be in healthy state and untreated orthodontically. Patients' records should each include a pretreatment lateral cephalogram of good quality.

As for the exclusion criteria, every patient with syndromes or cleft lip/palate, with systemic diseases, with previous traumas in the orofacial region, or on regular medications that may hinder the overall growth, were excluded from the study. Records with the lack of visibility and clarity of the second, third, or fourth cervical vertebra or the presence of congenital anomalies on these vertebras seen on the lateral cephalometric radiograph were also excluded from the study.

The research was conducted after clearance by the institutional ethical committee.

\section{Measurement Methods}

The radiographs of the subjects fulfilling these criteria were analyzed.

Staging of the skeletal maturation was made according to the original method of Baccetti et al. ${ }^{23}$ by calculating the depth of the concavity of the lower edge of $\mathrm{C} 2, \mathrm{C} 3$, and $\mathrm{C} 4(\mathrm{C} 2 \mathrm{~m}, \mathrm{C} 3 \mathrm{~m}$, and $\mathrm{C} 4 \mathrm{~m})$ and the ratios C3BAR, C3PAR, C4BAR, and C4PAR (Fig. 1 and Table 1).

When the stage of the skeletal maturation corresponded to CVM3 or CVM4, the case was selected and the operator (HG) determined the skeletal class according to three different measurements:

- Björk analysis: class I: $-0.5^{\circ}<\mathrm{A}-\mathrm{N}-\mathrm{Pog}<4^{\circ}$, class II: A-N-Pog $>4^{\circ}$

- Angle between the maxilla and the mandible (ANB) angle: class I: $\mathrm{ANB}=2^{\circ} \pm 2^{\circ}$, class II: ANB $>4^{\circ}$

- Witts analysis:
- Class I: boys: $\mathrm{AoBo}=-1 \mathrm{~mm} \pm 2 \mathrm{~mm}$, girls: $\mathrm{AoBo}=0 \mathrm{~mm} \pm$ $2 \mathrm{~mm}$

- Class Il: boys: AoBo $>1 \mathrm{~mm}$, girls: AoBo $>+2 \mathrm{~mm}$

Only subjects in skeletal class I and class II were included. After that the operator determined the vertical pattern using three different angles:

- $\mathrm{GOGN}-\mathrm{SN}: 32^{\circ} \pm 3^{\circ}$

- ANS-PNS/Go-Me: $25^{\circ} \pm 3^{\circ}$

- $F M A: 24^{\circ} \pm 3^{\circ}$

Each patient was assigned to his category for the anteroposterior and vertical dimensions, if at least two of the three measurements match the category.

Intra- and interobserver errors were calculated by selecting 35 random radiographs ( $10 \%$ of the sample). The radiographs were traced, 2 weeks later, by the same operator (HG) in addition to a second operator (NA) in order to determine the validity and reproducibility of the cephalometric measurements and reliability and consistency of the results between the two operators.

The calculation of the intraoperator error showed an excellent agreement for CVM staging (Chi-square $=0.866$ ), and good agreements for the determination of the skeletal class (Chi-square $=0.714$ ) and the facial vertical pattern (Chi-square $=$ 0.717). The calculation of the interoperator error showed a good agreement for CVM (Kappa = 0.715), and excellent agreements for the anteroposterior skeletal relationship (Kappa $=0.883)$ and the facial vertical pattern $($ Kappa $=0.868)$.

\section{Results}

346 subjects were included in the study (7,612 points were identified and 4,498 angles, distances, and ratios were calculated). The average age of the entire sample was $151.86 \pm 18.90$ months with a minimum of 97 months and a maximum of 203 months.

The distribution of the sample was according to the following variables: skeletal class, skeletal age, gender, and vertical patterns represented in Table 2.

The average onset age of the active pubertal growth and the duration of the pubertal peak were determined in each group in order to estimate the optimal dental orthopedic treatment timing and to analyze the maxillomandibular growth development.

Considering the skeletal classes of malocclusion, subjects in skeletal class I and class II have a start of active growth at the age of 12 years approximately, with no statistical difference between the groups for CVM3 and CVM4 (Table 3); however, a statistically significant difference ( $p=0.0001)$ was detected for the duration of the pubertal peak between class I (12.65 months) and class II (18.84 months) groups (Table 3).

Considering the gender, the active growth starts at the age of 11.56 years for girls, whereas for boys, it starts at 12.58 years; the duration of the pubertal peak is about 15.22 months for girls and 20.08 months for boys. A statistically significant difference was found for the onset age of the pubertal peak and the growth peak duration according to the gender (Table 4).

Considering the vertical pattern, the mean onset age of active growth is around 12 years for hypo- and normodivergent subjects and about 11.5 years for hyperdivergent subjects, with no statistical difference. The growth peak duration also differs between hypodivergent, normodivergent subjects (around 13 months 

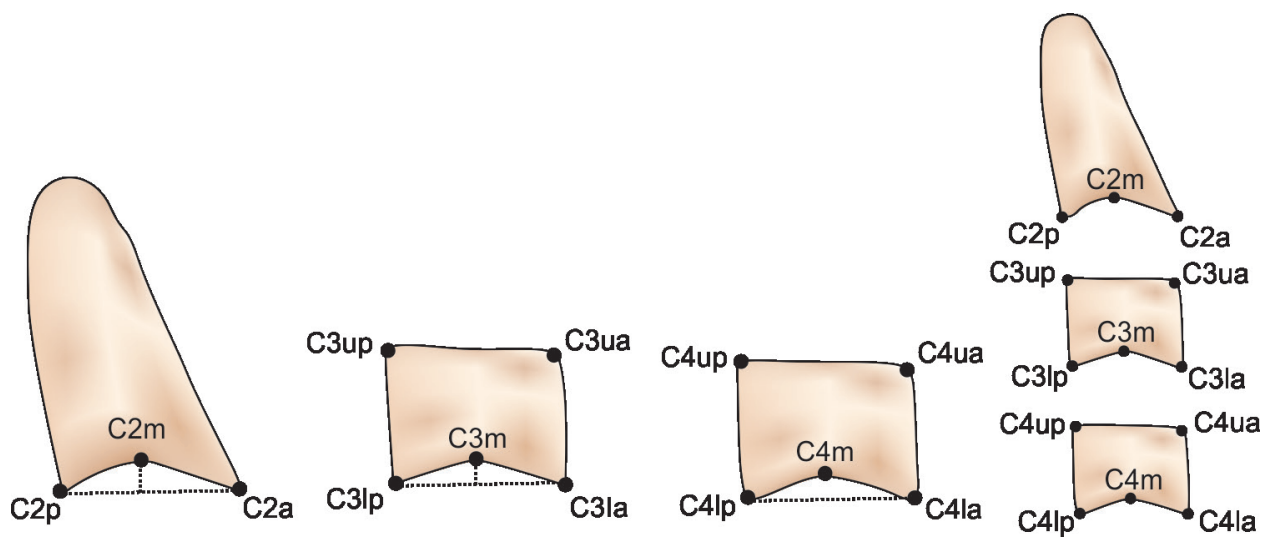

Fig. 1: Vertebral points and measures

Table 1: Vertebral points, measures, and ratios used to determine the vertebral stage

\begin{tabular}{|c|c|c|}
\hline \multicolumn{2}{|c|}{ Cephalometric landmarks } & \multirow{2}{*}{$\begin{array}{l}\text { Definition } \\
\text { Deepest point on the lower border of the body of C2 }\end{array}$} \\
\hline Vertebral points & $\mathrm{C} 2 \mathrm{~m}$ & \\
\hline & $\mathrm{C} 3 \mathrm{~m}$ & Deepest point on the lower border of the body of C3 \\
\hline & $\mathrm{C} 4 \mathrm{~m}$ & Deepest point on the lower border of the body of $\mathrm{C} 4$ \\
\hline & $\mathrm{C} 2 \mathrm{p}$ & Most posterior point on the lower border of the body of $\mathrm{C} 2$ \\
\hline & $\mathrm{C} 2 \mathrm{a}$ & Most anterior point on the lower border of the body of $C 2$ \\
\hline & C3up & Most superior point of the posterior border of the body of $\mathrm{C} 3$ \\
\hline & C3ua & Most superior point of the anterior border of the body of $\mathrm{C} 3$ \\
\hline & C3lp & Most posterior point on the lower border of the body of $\mathrm{C} 3$ \\
\hline & C3la & Most anterior point on the lower border of the body of $\mathrm{C} 3$ \\
\hline & C4up & Most superior point of the posterior border of the body of $\mathrm{C} 4$ \\
\hline & C4ua & Most superior point of the anterior border of the body of $\mathrm{C} 4$ \\
\hline & C4Ip & Most posterior point on the lower border of the body of $\mathrm{C} 4$ \\
\hline & C4la & Most anterior point on the lower border of the body of $\mathrm{C} 4$ \\
\hline \multirow[t]{7}{*}{ Measures and ratios } & Conc C2 & Measure of the concavity depth at the lower border of C2 (distance from $C 2 p-C 2 a$ to $C 2 m$ ) \\
\hline & Conc C3 & Measure of the concavity depth at the lower border of $\mathrm{C} 3$ (distance from $\mathrm{C} 3 \mathrm{lp}-\mathrm{C} 3 \mathrm{la}$ to $\mathrm{C} 3 \mathrm{~m}$ ) \\
\hline & Conc C4 & Measure of the concavity depth at the lower border of C4 (distance from C4Ip-C4la to C4m) \\
\hline & C3BAR & $\begin{array}{l}\text { Ratio between the length of the base (distance C3lp-C3la) and the anterior height } \\
\text { (distance C3ua-C3la) of the body of } \mathrm{C} 3\end{array}$ \\
\hline & C3PAR & $\begin{array}{l}\text { Ratio between the posterior (distance C3up-C3lp) and anterior (distance C3ua-C3la) } \\
\text { heights of the body of } \mathrm{C} 3\end{array}$ \\
\hline & C4BAR & $\begin{array}{l}\text { Ratio between the length of the base (distance C4lp-C4la) and the anterior height } \\
\text { (distance C4ua-C4la) of the body of C4 }\end{array}$ \\
\hline & C4PAR & $\begin{array}{l}\text { Ratio between the posterior (distance C4up-C4lp) and anterior (distance C4ua-C4la) } \\
\text { heights of the body of C4 }\end{array}$ \\
\hline
\end{tabular}

Table 2: Distribution of the samples according to the variables: skeletal class, skeletal age, gender, and vertical pattern

\begin{tabular}{lllll}
\hline Variable & Group & Effective & Percentage & Total effective \\
\hline Skeletal class & Class I & 198 & 57.2 & 346 \\
\multirow{2}{*}{ Skeletal age } & Class II & 148 & 42.8 & \\
& CVM3 & 171 & 49.4 & 346 \\
Gender & CVM4 & 175 & 50.6 & \\
\multirow{5}{*}{ Vertical pattern } & Boys & 131 & 37.9 & 346 \\
& Girls & 215 & 62.1 & \\
& Hypodivergent & 143 & 41.3 & 346 \\
& Normodivergent & 120 & 34.7 & \\
\hline
\end{tabular}


Table 3: Mean age, standard deviation, and the duration of the adolescent peak growth spurt according to classes of maolocclusion (class I/class II). $t$ test results for comparing class I and class II for the variables CVM3, CVM4, and growth peak duration

\begin{tabular}{|c|c|c|c|c|c|c|c|c|}
\hline Variables & & & $n$ & $\begin{array}{l}\text { Mean onset age } \\
\text { months (years) }\end{array}$ & $\begin{array}{l}\text { SD months } \\
\text { (years) }\end{array}$ & $\begin{array}{l}\text { t test for comparing } \\
\text { class I and class II }\end{array}$ & $\begin{array}{l}\text { Adolescent peak } \\
\text { growth spurt duration } \\
\text { CVM4-CVM3 months } \\
\text { (years) }\end{array}$ & $\begin{array}{l}\text { t test for comparing } \\
\text { class I and class II }\end{array}$ \\
\hline \multirow{4}{*}{$\begin{array}{l}\text { Skeletal } \\
\text { class-CVM }\end{array}$} & \multirow[t]{2}{*}{ Class I } & CVM 3 & 96 & $145.94(12.162)$ & $17.494(1.458)$ & \multirow[t]{2}{*}{ For CVM3 $p=0.115$} & \multirow[t]{2}{*}{$12.65(1.054)$} & \multirow{4}{*}{$\begin{array}{l}\text { For pubertal peak } \\
\text { duration } \\
p=0.0001^{*}\end{array}$} \\
\hline & & CVM 4 & 102 & $158.59(13.21)$ & $17.033(1.419)$ & & & \\
\hline & \multirow[t]{2}{*}{ Class II } & CVM 3 & 75 & $141.76(11.813)$ & $16.549(1.379)$ & \multirow[t]{2}{*}{ For CVM4 $p=0.452$} & \multirow[t]{2}{*}{$18.84(1.570)$} & \\
\hline & & CVM 4 & 73 & $160.60(13.383)$ & $18.006(1.501)$ & & & \\
\hline
\end{tabular}

*Significance is at $p<0.05$

Table 4: Mean age, standard deviation, and the duration of the adolescent peak growth spurt according to gender. $t$ test result for comparing girls and boys for the variables: CVM3, CVM4, and growth peak duration

\begin{tabular}{|c|c|c|c|c|c|c|c|c|}
\hline Variables & & & $n$ & $\begin{array}{l}\text { Mean onset age } \\
\text { months (years) }\end{array}$ & $\begin{array}{l}\text { SD months } \\
\text { (years) }\end{array}$ & $\begin{array}{l}\text { t test for comparing } \\
\text { class I and class II }\end{array}$ & $\begin{array}{l}\text { Adolescent peak } \\
\text { growth spurt duration } \\
\text { CVM4-CVM3 months } \\
\text { (years) }\end{array}$ & $\begin{array}{l}\text { t test for comparing } \\
\text { class I and class II }\end{array}$ \\
\hline \multirow{4}{*}{$\begin{array}{l}\text { Gender- } \\
\text { CVM }\end{array}$} & \multirow{2}{*}{$\begin{array}{l}\text { Girls } \\
(n=215)\end{array}$} & CVM 3 & 96 & $138.74(11.562)$ & $15.254(1.271)$ & \multirow[t]{2}{*}{ For CVM3 $p=0.0001^{*}$} & \multirow[t]{2}{*}{$15.22(1.268)$} & \multirow{4}{*}{$\begin{array}{l}\text { For pubertal } \\
\text { peak duration } \\
p=0.0001^{*}\end{array}$} \\
\hline & & CVM 4 & 119 & $153.96(12.830)$ & $16.057(11.338)$ & & & \\
\hline & \multirow{2}{*}{$\begin{array}{l}\text { Boys } \\
(n=131)\end{array}$} & CVM 3 & 75 & $150.97(12.581)$ & $17.112(1.426)$ & \multirow[t]{2}{*}{ For CVM4 $p=0.0001^{*}$} & \multirow[t]{2}{*}{$20.08(1.673)$} & \\
\hline & & CVM 4 & 56 & $171.05(14.254)$ & $14.311(1.193)$ & & & \\
\hline
\end{tabular}

*Significance is at $p<0.05$

Table 5: Mean, standard deviation, and duration of the adolescent peak growth spurt according to the vertic al growth pattern. Results of Scheffe's multicomparison test for the growth duration between different vertical growth patterns

\begin{tabular}{|c|c|c|c|c|c|c|c|}
\hline Variables & & & $n$ & $\begin{array}{l}\text { Mean onset age } \\
\text { months (years) }\end{array}$ & $\begin{array}{l}\text { SD months } \\
\text { (years) }\end{array}$ & $\begin{array}{l}\text { Adolescent peak } \\
\text { growth spurt duration } \\
\text { months (years) }\end{array}$ & $\begin{array}{l}\text { Scheffe's multicomparison } \\
\text { test for growth duration } \\
\text { between }\end{array}$ \\
\hline \multirow{6}{*}{$\begin{array}{l}\text { Vertical } \\
\text { pattern-CVM }\end{array}$} & \multirow{2}{*}{$\begin{array}{l}\text { Hypodivergents } \\
(n=143)\end{array}$} & CVM 3 & 69 & $147.71(12.309)$ & $14.835(1.236)$ & $13.15(1.096)$ & Hypo-Normo $p=0.874$ \\
\hline & & CVM 4 & 74 & $160.86(13.405)$ & $17.827(1.485)$ & & \\
\hline & \multirow{2}{*}{$\begin{array}{l}\text { Normodivergents } \\
(n=120)\end{array}$} & CVM 3 & 79 & $145.96(12.163)$ & $16.692(1.391)$ & $13.31(1.109)$ & Hypo-Hyper: $p=0.001^{*}$ \\
\hline & & CVM 4 & 41 & $159.27(13.273)$ & $16.404(1.367)$ & & \\
\hline & \multirow{2}{*}{$\begin{array}{l}\text { Hyperdivergents } \\
(n=83)\end{array}$} & CVM 3 & 50 & $137.80(11.483)$ & $18.627(1.552)$ & $17.93(1.494)$ & Normo-Hyper: $p=0.001^{*}$ \\
\hline & & CVM 4 & 33 & $155.73(12.977)$ & $17.787(1.482)$ & & \\
\hline
\end{tabular}

*Significance is at $p<0.05$

for both), and hyperdivergent subjects (around 18 months). This difference is statistically significant (Table 5).

When class I/class II groups were analyzed according to the skeletal maturation and stratified first for gender and second for vertical pattern, multiple group comparisons showed that in skeletal class II cases, boys and hypodivergent as well as hyperdivergent subjects have a longer duration of the pubertal peak growth spurt (Table 6).

\section{Statistical Analysis}

The Statistical Package for Social Sciences Software (SPSS for Windows, version 20.0, Chicago, IL, USA) was used to perform the statistical analysis (significance level: $p$ value $<0.05$ ). The normality of the distributions was verified using the Kolmogorov-Smirnov test.

Descriptive statistics were used to define samples characteristics as for the mean, standard deviation, and growth duration.

Levene's test was chosen to demonstrate the equality of variances between each two independent samples tested.

Then their averages were compared using the independent samples $t$ test to determine any statistical difference.
ANOVA and Scheffe's multicomparison tests were used to calculate a possible difference between the average of several samples.

\section{Discussion}

Determining the pubertal peak duration has taken an increased importance especially for the orthopedic treatment of the craniofacial discrepancies. The clinical interest of this study estimating and comparing the duration of the pubertal peak growth spurt in white Caucasian subjects untreated orthodontically is the stratification according to skeletal classes, gender, and vertical patterns.

In comparison with the study of Kuc-Michalska and Baccetti (218 subjects) $)^{28}$ and the study of Salazar-Lazo et al. (154 subjects), ${ }^{29}$ the originality of the present study resides in a larger sample size (346 subjects), in the sample stratification according to the gender and facial pattern and in the sample selection based on three cephalometric anteroposterior values and three vertical values in order to confirm the skeletal diagnosis. The staging of the skeletal maturation in the sample was defined based on the measurements 
Table 6: Comparison of the duration of the adolescent peak growth spurt for subjects in skeletal class I/class II according to the gender and vertical growth pattern

\begin{tabular}{|c|c|c|c|c|c|}
\hline Variables & & CVM 3 months (years) & CVM 4 months (years) & $\begin{array}{l}\text { Adolescent peak growth } \\
\text { spurt duration CVM4- } \\
\text { CVM3 months (years) }\end{array}$ & $\begin{array}{l}\text { t test for comparing peak } \\
\text { growth spurt duration between } \\
\text { class I and II }\end{array}$ \\
\hline \multirow[t]{2}{*}{ Class I } & Girls & $140.77(11.73)$ & $154.19(12.85)$ & $13.42(1.12)$ & For girls $p=0.372$ \\
\hline & Boys & $153.18(12.77)$ & $168.22(14)$ & $15.04(1.23)$ & \\
\hline \multirow[t]{2}{*}{ Class II } & Girls & $135.90(11.33)$ & $153.63(12.80)$ & $17.73(1.47)$ & For boys $p=0.0001^{*}$ \\
\hline & Boys & $148.46(12.37)$ & $174.83(14.57)$ & $26.37(2.2)$ & \\
\hline \multirow[t]{3}{*}{ Class I } & Hypodivergent & $149.93(12.49)$ & $159.07(13.25)$ & $9.14(0.77)$ & For hypodivergent $p=0.0001^{*}$ \\
\hline & Normodivergent & $149(12.42)$ & $160(13.33)$ & $11(0.91)$ & \\
\hline & Hyperdivergent & $137.93(11.49)$ & $153.08(12.76)$ & $15.15(1.27)$ & For normodivergent $p=0.12$ \\
\hline \multirow[t]{3}{*}{ Class II } & Hypodivergent & $144.91(12.08)$ & $164(13.67)$ & $19.09(1.59)$ & \\
\hline & Normodivergent & $142.23(11.85)$ & $158.15(13.18)$ & $15.92(1.33)$ & For hyperdivergent $p=0.001^{*}$ \\
\hline & Hyperdivergent & $137.62(11.47)$ & $157.45(13.12)$ & $19.82(1.65)$ & \\
\hline
\end{tabular}

*Significance is at $p<0.05$

and ratios determined by the original method of Baccetti et al. ${ }^{28}$ and not on visual assessment used in other studies.

This study showed that the age of the onset of active growth is similar for both skeletal groups, class I (12 years and 2 months) and class II (11 years and 10 months), with a statistically significant difference of the peak duration (13 months and 19 months, respectively). The duration of the growth spurt is similar between this study with the results found by Kuc-Michalska and Baccetti ${ }^{28}$ who found that the age at the onset of the active growth is 11 years and 5 months and the duration of the growth spurt in patients with skeletal class I is 11 months.

The results showed that the duration of the pubertal peak is bigger for the class II group when compared to the Class I group. Therefore, the development of a class II malocclusion could not be explained by a shorter duration of the pubertal peak. This is in contradiction with other studies, as Salazar-Lazo et al. ${ }^{29}$ found that the duration of the adolescent peak growth spurt for Class II malocclusion subjects is smaller then class I subjects, while KucMichalska and Baccetti ${ }^{28}$ have proved a longer duration of the pubertal peak for the skeletal class III subjects when compared to class I subjects and they related the larger increases in mandibular length to the longer duration of the pubertal peak in class III subjects.

The development of a class II discrepancy might involve other causes than the duration of the growth peak, such as the growth magnitude (amount of growth) and different growth directions. Bishara et al. ${ }^{9}$ investigated the growth in magnitude and direction and found that class II division 1 subjects might have a late mandibular growth due to a "catch up" period, although the comparison of the growth magnitude indicated a greater skeletal and soft tissue convexities in Class II Division 1 subjects accompanied by a tendency for a more retruded mandible. It is important to mention that mandibular growth leading to reduced mandibular length has controversial evidence since multiple studies found that the mandibular length can be significantly shorter in class II patients, ${ }^{9,30-33}$ similar to the subjects in skeletal class $1^{34}$ or even higher in skeletal class II subjects. ${ }^{35}$

Excessive maxillary growth or anteriorly positioned maxilla, ${ }^{36,37}$ retrusive mandibular position due to a posterior position of the glenoid cavity, ${ }^{30,38,39}$ vertical growth or clockwise mandibular rotation, ${ }^{35,38,41}$ early onset of the skeletal class II discrepancy, abnormal muscular function, and combination of several factors ${ }^{38-40,42}$ can all lead to an establishment of skeletal problems at a young age with a subsequent worsening of this discrepancy and an alteration in size and shape of the mandible.

These results suggest that the reorientation of the direction of growth and stimulation of the mandibular growth potential would be necessary in order to correct a skeletal class II discrepancy and that the longer period of active growth in these patients would be a favorable factor.

The cross-sectional study also being a limitation to these kinds of research it was used because of the high risk of radiographic exposure that could occur in a longitudinal study. Subjects were matched for skeletal class, gender, and skeletal pattern.

When comparing genders, the results of this study showed that the age of onset of active growth is 1 years 6 months and 12 years 6 months for girls and boys, respectively, with the duration of growth of approximately 15 months and 20 months successively. Clear differences with other authors are noted (duration of active growth = Hunter: 2.57 years, Bowden: 2.89 years, Tarranger and Hägg: 94 years for girls and 1.96 years for boys) probably due to ethnic polymorphisms and differences in the sample size.

This study found that this difference is statistically significant for boys, whereas the study conducted by Kuc-Michalska and Baccetti ${ }^{28}$ did not detect any statistically significant difference. This can be explained by the difference in the sample size. This suggests that the timing of the treatment should differ according to gender.

When the sample was divided according to the vertical pattern, this study showed a significant difference in comparing the age of onset of the active growth and the duration of the pubertal peak in three groups: the hyperdivergent subjects present the earliest age of onset of puberty compared to hypodivergent and normodivergent subjects (these two being comparable: about 11 years 6 months and 12 months, respectively). The duration of the pubertal peak is also different between the 3 groups: hyperdivergent subjects have the longest duration (19 months while the estimated duration in hypodivergent and normodivergent subjects is 13 months).

This emphasizes that hyperdivergent subjects present an earlier onset of the vertical growth that can be explained by a hypodevelopment of the posterior facial height, a hyperdeveloppement of the anterior facial height, a posterior rotation of the mandible" or an "anterior hyporotation" due to a 
reduced intramatrix growth compared to the normal growth during the 12-15 years of interval. ${ }^{43}$

When the class I/class II groups were analyzed according to skeletal maturation, gender, and vertical pattern, a statistically significant difference was found for all groups. Boys and hyperdivergent subjects have an earlier onset of active growth and a longer duration of the pubertal peak. These results emphasized the necessity of detecting the right treatment timing according to gender and marked the difficulty in treating a class II hyperdivergent patient. The vertical control should be initiated at a younger age and for a longer period of active growth to enhance the outcome.

Future studies should consider the determination of the cephalometric etiology of the skeletal class II and divide the class II group into class II division 1 and class II division 2, in addition to adopting a longitudinal methodology instead of a cross-sectional one in order to give more accurate results and/or redo the same study in a 3D methodology.

\section{ConcLusion}

Our primary objective was to estimate the duration of the pubertal peak in white Caucasian subjects untreated orthodontically according to the skeletal anteroposterior relationship, gender, and vertical pattern. The secondary objective was to determine the existence of a difference between skeletal class I and class II subjects when analyzed according to the gender and skeletal pattern.

- The age of onset of the active growth is approximately 12 years for subjects in skeletal class I and class II relationship; this age differs between girls and boys ( 11 years 7 months and 12 years 7 months, respectively), and it is earlier in hyperdivergent subjects compared to hypodivergent and normodivergents subjects (11 years 6 months, 12 years 4 months, and 12 years 2 months, respectively).

- The duration of the pubertal peak is 13 months for subjects in skeletal class I relationship and 19 months for subjects in skeletal class II relationship (this difference is statistically significant); it differs between girls and boys (15 months and 20 months, respectively) and between hypodivergent, normodivergent, and hyperdivergent subjects (13 months and 18 months, respectively).

- The persistence of a skeletal discrepancy in class II subjects despite the presence of a "normal" period of active growth can be explained by (1) a mandibular retrusion due to a reduced mandibular length or a posterior positioning of the mandible, (2) an excess growth of the maxilla, (3) a hyperdivergent vertical pattern of growth leading to a distalization of the Gonion point, and (4) a combination of other several factors.

\section{References}

1. Björk A, Helm S. Prediction of the age of maximum pubertal growth in body height. Angle Orthod 1967;37:134-143.

2. Tarranger J, Hägg U. The timing and duration of adolescent growth. Acta Odontol Scand 1979;38:57-67. DOI: 10.3109/00016358008997719.

3. Hunter $C$. The correlation of facial growth with body height and skeletal maturation at adolescence. Angle Orthod 1966;36: 44-54.

4. Bowden B. Epiphyseal changes in the hand/wrist area as indicators of adolescent stage. Aust Orthod J 1976;4:87-104.

5. Fishman L. Chronological vs skeletal age, an evaluation of craniofacial growth. Angle Orthod 1979;49:181-189.
6. Engel TP, Renkema AM, et al. The cervical vertebral maturation (CVM) method cannot predict craniofacial growth in girls with class II malocclusion. Eur J Orthod 2016 Feb;38:1-7. DOI: 10.1093/ejo/cju085.

7. Gray S, Bennani $\mathrm{H}$, et al. Morphometric analysis of cervical vertebrae in relation to mandibular growth. Am J Orthod Dentofacial Orthop 2016;149:92-98. DOI: 10.1016/j.ajodo.2015.06.028.

8. Nanda R-S. The rates of growth of several facial components measured from serial cephalometric roentgenograms. Am J Orthod Dentofacial Orthop 1955;41:658-673. DOI: 10.1016/0002-9416(55)90112-3.

9. Bishara S, Jakobsen J, et al. Changes in dentofacial structures in untreated $\mathrm{Cl}$ II division 1 and normal subjects. Angle Orthod 1997;67:55-66.

10. Mellion ZJ, Behrens RG, et al. The pattern of facial skeletal growth and its relationship to various common indexes of maturation. Am J Orthod Dentofacial Orthop 2013;143:845-854.

11. Tofani M. Mandibular growth at puberty. Am J Orthod 1972;62: 176-195. DOI: 10.1016/0002-9416(72)90141-8.

12. Hägg $U$, Taranger J. Menarche and voice change as indicators of the pubertal growth spurt. Acta Odontol Scand 1980;38:179-186. DOI: 10.3109/00016358009004718.

13. Björk A, Skieller V. Facial development and tooth eruption: an implant study at the age of puberty. Am J Orthod 1972;62:339-383. DOI: 10.1016/S0002-9416(72)90277-1.

14. Chertkow S, Fatti P. The relationship between tooth mineralization and early radiographic evidence of the ulnar sesamoid. Angle Orhod 1979;49:282-288.

15. Mappes $M$, Harris $E$, et al. An example of regional variation in the tempos of tooth mineralization and hand-wrist ossification. Am J Orthod Dentofacial Orthop 1992;101:145-151. DOI: 10.1016/08895406(92)70006-V.

16. Krailassiri S, Anuwongnukroh N, et al. Relationships between dental calcification stages and skeletal maturity indicators in Thai individuals. Angle Orthod 2002;72:155-166.

17. Başaran G, Özer T, et al. Cervical vertebral and dental maturity in Turkish subjects. AmJ Orthod Dentofacial Orthop 2007;131: 447.e13-447.e20. DOI: 10.1016/j.ajodo.2006.08.016.

18. Smith R. Misuse of hand-wrist radiographs. Am J Orthod 1980;77: 75-78. DOI: 10.1016/0002-9416(80)90225-0.

19. Kumar S, Singla A, et al. Skeletal maturation evaluation using mandibular second molar calcification stages. Angle Orthod 2011;81:872-877. DOI: 10.2319/110610-646.1.

20. Lamparski DG. Skeletal Age Assessment Utilizing Cervical Vertebrae. Angle Orthod 1972;67:458-460. DOI: 10.1016/0002-9416(75)90038-X.

21. Hassel B, Farman A, et al. Skeletal maturation evaluation using cervical vertebrae. Am J Orthod Dentofacial Orthop 1995;107:58-66. DOI: 10.1016/S0889-5406(95)70157-5.

22. Franchi L, Baccetti T, et al. Mandibular growth as related to cervical vertebral maturation and body height. Am J Orthod Dentofac Orthop 2000;118:335-340. DOI: 10.1067/mod.2000.107009.

23. Baccetti T, Franchi L, et al. The Cervical Vertebral Maturation (CVM) Method for the Assessment of Optimal Treatment Timing in Dentofacial Orthopedics. Semin Orthod 2005;11:119-129. DOI: 10.1053/j.sodo.2005.04.005.

24. Seedat A, Forsberg C. An evaluation of the third cervical vertebra (C3) as a growth indicator in Black subjects. SADJ 2005;60:156-160.

25. Jaqueira $L$, Armond $M$, et al. Determining skeletal maturation stage using cervical vertebrae: evaluation of three diagnostic methods. Braz Oral Res 2010;24:433-437. DOI: 10.1590/S1806-83242010000400010.

26. Rainey BJ, Burnside G, et al. Reliability of cervical vertebral maturation staging. Am J Orthod Dentofacial Orthop 2016;150:98-104. DOI: 10.1016/j.ajodo.2015.12.013.

27. Dolce C, McGorray S, et al. Timing of class II treatment: Skeletal changes comparing 1-phase and 2-phase treatment. Am J Orthod Dentofacial Orthop 2007;132:481-489. DOI: 10.1016/ j.ajodo.2005.08.046.

28. Kuc-Michalska M, Baccetti T. Duration of the pubertal peak in skeletal Cl I and CI III subjects. Angle Orthod 2010;80:54-57. DOI: 10.2319/020309-69.1. 
29. Salazar-Lazo R, Arriola-Guillén LE, et al. Duration of the peak of adolescent growth spurt in class I and II malocclusion subjects using a cervical vertebrae maturation analysis. Acta Odontol Latinoam 2014;27(2):96-101.

30. Craig CE. The skeletal patterns characteristics of class I and class II, division I malocclusion in normalateralis. Angle Orthod 1951;21: 44-56.

31. Reidel RA. The relation of maxillary structures to cranium in malocclusion and normal occlusion. Angle Orthod 1952;22:142-145.

32. Class II division 1 and class II division 2 (Angle) malocclusion. Angle Orthod 1954;24:106-119.

33. Harris J, Kowalski C, et al. Discrimination between normal and class II individuals using Steiner's analysis. Angle Orthod 1972;42:212-220.

34. Rothstein T. Facial morphology and growth from 10 to 14 years of age in children presenting class II, division 1 malocclusion: a comparative roentgenographic cephalometric study. Am J Orthodont 1971;60:619-620. DOI: 10.1016/0002-9416(71)90202-8.

35. Altemus L. Horizontal and vertical dentofacial relationships in normal and class II, division 1 malocclusion in girls 11-15 years. Angle Orthod 1955;25:120-137.
36. Fisk $G$, Culbert $M$, et al. The morphology and physiology of distocclusion. Am J Orthodont 1953;39:3-12. DOI: 10.1016/00029416(53)90092-X.

37. Rosenblum R. Class II malocclusion: mandibular retrusion or maxillary protrusion? Angle Orthod 1995;65:49-62.

38. Henry RG. A classification of class II, division 1 malocclusion. Angle Orthod 1957;27:83-92.

39. McNamara Jr JA. Components of class II malocclusion in children 8-10 years of age. Angle Orthod 1981;51:177-202.

40. Pancherz H, Zieber K, et al. Cephalometric characteristics of class II division 1 and class II division 2 malocclusions: a comparative study in children. Angle Orthod 1997;67:111-120.

41. Drelich RC. A cephalometric study of untreated class II, division 1 malocclusion. Angle Orthod 1948;18:70-75.

42. Ngan P. Longitudinal evaluation of growth changes in $\mathrm{Cl}$ II division 1 subjects. Semin Orthod 1997;3:222-231. DOI: 10.1016/S10738746(97)80055-2.

43. Karlsen AT. Association between facial height development and mandibular growth rotation in low and high MP-SN angle faces: a longitudinal study. Angle Orthod 1997;67:103-110. 